Linha D'Água (Online), São Paulo, v. 33, n. 1, p. 9-29, jan.-abr. 2020

\title{
UM ESTUDO DO TERMO FISCAL NA TERMINOLOGIA DA ECONOMIA: PROCESSOS DE FORMAÇÃO E INFORMAÇÕES CONCEITUAIS
}

\section{A STUDY OCCURRENCES OF THE FISCAL TERM IN ECONOMICS TERMINOLOGY: FORMATION PROCESSES AND CONCEPTUAL INFORMATIONS}

\author{
Lucimara Alves Costa* \\ Universidade de São Paulo, São Paulo, SP, Brasil \\ Ieda Maria Alves** \\ Universidade de São Paulo, São Paulo, SP, Brasil
}

\begin{abstract}
Resumo: Neste trabalho, temos por objetivo analisar as ocorrências do termo fiscal em um corpus da terminologia da Economia, com o intuito de verificar os padrões de formação mais recorrentes constituídos por esse adjetivo, as informações semânticas veiculadas pelos termos sintagmáticos de que ele faz parte, bem como uma possível relação entre os termos próprios do domínio da Economia com outras áreas de conhecimento, principalmente pelo emprego de metáforas conceituais. Para tanto, pautamo-nos nos pressupostos da Morfologia de especialidade e da Terminologia. A metodologia seguida consistiv em duas fases: uma análise quantitativa por meio da seleção das lexias com utilização do programa Wordsmith Tools e uma análise quantitativa dos termos selecionados, na qual verificamos o processo de formação e o "que quer dizer" cada uma dessas construções. Como resultados, esperamos que este estudo contribua para uma melhor caracterização e conhecimento de como se constitui a terminologia da Economia, uma vez que fiscal é um dos termos de maior ocorrência nessa área de especialidade, estando vinculado a diversas outras lexias e participando de distintos padrões de formação.
\end{abstract}

Palavras-chave: terminologia; Morfologia; Economia; processos de formação de termos; fiscal.

\begin{abstract}
In this paper, we aim at analyzing the occurrences of fiscal term in an Economics terminology corpus, in order to verify the most recurrent formation patterns constituted by this adjective, the semantic information conveyed by the syntagmatic terms of which it is part, as well as a possible relation between the specific terms in the field of Economics and other areas of knowledge, primarily through the use of conceptual metaphors. For this purpose, we had a as basis the assumptions of the major Morphology and Terminology. The methodology consisted of two phases: a quantitative analysis through the selection of lexias using the Wordsmith Tools program and a quantitative analysis of the selected terms, in which we verified the formation process and the meaning of each construction. As a result, we expect that this study will contribute to a better characterization and knowledge of how the Economics terminology is constituted, since the word fiscal is one of the most recurrent terms in this area of expertise, being linked to several other lexias and partaking in different formation patterns.
\end{abstract}

Keywords: Terminology; Morphology; Economics; Term Formation Processes; Fiscal.

* Pós-Doutoranda da Universidade de São Paulo - USP, São Paulo, SP, Brasil; lucimara@usp.br

** Professora titular da Universidade de São Paulo - USP, São Paulo, SP, Brasil; iemalves@usp.br

http://dx.doi.org/10.11606/issn.2236-4242.v33ilp9-29

Todo conteúdo da Linha D’Água está sob Licença Creative Commons Attribution-NonCommercial 4.0 International License 
Linha D'Água (Online), São Paulo, v. 33, n. 1, p. 9-29, jan.-abr. 2020

\section{Introdução'}

Com a progressiva internacionalização da ciência, ocorrida a partir do século XIX, surgiu, por parte dos cientistas, a preocupação e necessidade de se estabelecerem regras sistemáticas de formação dos termos de suas respectivas disciplinas. Nesse contexto, situam-se as origens da Teoria Geral da Terminologia (TGT), criada pelo engenheiro austríaco Eugen Wüster e que tinha por objetivo a estandardização e normatização da linguagem especializada. De acordo com essa teoria, os termos são considerados unidades estáticas e dissociadas de seu contexto de produção, estabelecendo uma relação biunívoca com seus respectivos conceitos.

Para Wüster (1998), os termos (objetos de estudo da Terminologia) representam unidades lógicas e unívocas em seu conteúdo, uso e função e, sendo assim, seu valor somente se define em sua relação com o âmbito no qual se inserem. Um termo pertence a um único campo especializado, e cada campo especializado possui seus próprios termos.

Contudo, sabemos que essa afirmação não se confirma, pois, como bem destaca Rey (1995, p. 91), a existência da monossemia absoluta, bem como a ausência da sinonímia e ambiguidade são apenas ilusões e aspirações que não correspondem à realidade. Como assinalam autores como Sager (1990) e Krieger (2006), a Terminologia é uma área de interfaces, principalmente com a Tradução e a Documentação e, da mesma forma, acreditamos que os termos considerados próprios de um domínio específico se entrelaçam com termos de outras áreas de conhecimento, dando origem a formações complexas e muitas vezes metafóricas, que em nada correspondem ao sentido literal e unívoco, entre termo e conceito, pretendido por Wüster na Teoria Geral da Terminologia (TGT).

Desse modo, neste estudo, temos por objetivo analisar as ocorrências do termo fiscal em um corpus terminológico da Economia, de forma a verificar os padrões de formação sintagmática mais recorrentes observados com essa lexia, bem como as informações semânticas veiculadas por essas formações lexicais, evidenciando

1 Otrabalho é resultado parcial do Projeto de Pós-Doutorado intitulado "As várias faces da Economia: um estudo contrastivo sobre a variação denominativa entre Brasil e Espanha", financiado pela FAPESP, processo n: 2019/11136-7.

COSTA, L. A. C., ALVES, I. M. Um estudo do termo fiscal na terminologia da Economia: processos de formação e informações conceituais 
Linha D’Água (Online), São Paulo, v. 33, n. 1, p. 9-29, jan.-abr. 2020

o papel desse adjetivo e a relação entre a terminologia da Economia com outros domínios, por meio do emprego de metáforas conceituais.

Para melhor compreensão desta proposta, o trabalho está dividido em 3 partes: na primeira, apresentamos uma reflexão sobre a terminologia da Economia; na segunda parte, detalhamos a metodologia utilizada neste estudo e, em terceiro lugar, apresentamos nossa análise sobre o processo de formação das construções com a lexia fiscal e as informações semânticas relacionadas a essas unidades. Posteriormente, passamos às considerações finais e às referências bibliográficas utilizadas.

\section{A terminologia da Economia}

Muitos estudos têm abordado a relação entre denominação e conceito nas línguas de especialidade. Benveniste, em "Genèse du terme "scientifique" (Problèmes de linguistique générale), também enfatiza o papel da denominação em uma ciência. Para o autor:

A constituição de uma terminologia própria marca, em toda ciência, o início ou o desenvolvimento de uma conceptualização nova, e isso faz com que ela assinale um momento decisivo de sua história. Poder-se-ia mesmo dizer que a própria história de uma ciência se resume na de seus termos. Uma ciência somente começa a existir ou impor-se na medida em que ela impõe seus conceitos por meio de suas denominações. Ela não tem outro meio de impor sua legitimidade se não especificar seu objeto por meio de sua denominação, objeto esse que pode ser uma ordem de fenômenos, um domínio novo ou um modo novo de relação entre determinados dados. A aparelhagem mental consiste primeiramente em um inventário de termos que registram, configuram ou analisam a realidade. Denominar, isto é, criar um conceito, é a operação ao mesmo tempo primeira e última de uma ciência (BENVENISTE, 1974, p. 247)

No tocante à Economia não é diferente. A Economia é definida, no Dicionário Houaiss (2012), como "a ciência que estuda os fenômenos relacionados com a obtenção e a utilização dos recursos necessários ao bem-estar”. Essa característica, que implica a totalidade dos seres humanos e suas atividades, reflete-se no emprego

COSTA, L. A. C., ALVES, I. M. Um estudo do termo fiscal na terminologia da Economia: processos de formação e informações conceituais 
Linha D’Água (Online), São Paulo, v. 33, n. 1, p. 9-29, jan.-abr. 2020

da terminologia da Economia nas diferentes seções dos meios de comunicação de massa, como ressalta Alves:

A Economia é uma ciência muito presente na vida cotidiana dos cidadãos e, por essa razão, está representada não apenas nos cadernos de Economia específicos dos grandes jornais, mas também em todas as seções (Política, Esportes, Ciência, Cotidiano...) [...]. Como consequência, não raro encontramos definições de termos dessa ciência, que procuram explicitar o conceito de um termo para leitores não especializados. (2016, p. 48)

Como exemplos dessas unidades terminológicas, a autora apresenta os termos flippagem e home broker, referindo-se, no primeiro caso, à "gíria dos pequenos investidores para a operação que consiste em entrar na oferta, embolsar um ganho rápido e vender os papéis em seguida» e, no segundo caso, ao «sistema de negociação via internet que permite efetuar operações instantaneamente":

$\mathrm{Na}$ oferta de ações do Santander, os correntistas do banco foram beneficiados com direito de preferência no caso de rateio dos papéis. O que alguns clientes não sabem é que terão de se submeter a uma restrição operacional, capaz de inviabilizar eventual "flippagem", a gíria dos pequenos investidores para a operação que consiste em entrar na oferta, embolsar um ganho rápido e vender os papéis em seguida. Esses clientes terão de efetuar suas vendas e compras por telefone na mesa de operações das corretoras de Real ou Santander, o que pode demorar algum tempo. Ou seja, não terão acesso à comodidade do "home broker", o sistema de negociação via internet que permite efetuar operações instantaneamente. No segundo dia, porém, a ação estará no "bome broker", que funcionará normalmente. $<$ FSP_02/10/2009_MER_TONI SCIARRETTA > (ALVES, 2016, p. 49)

A análise das denominações destacadas no exemplo acima permite-nos constatar que, embora os enunciados definitórios ${ }^{2}$ - muito usuais em corpora de divulgação - que se seguem às unidades terminológicas tenham facilitado a compreensão do conceito por parte de leitores leigos e não acostumados com a terminologia da

2 Entende-se por enunciado definitório a paráfrase ou explicação que se apresenta de um termo com o intuito de defini-lo.

COSTA, L. A. C., ALVES, I. M. Um estudo do termo fiscal na terminologia da Economia: processos de formação e informaç̦es conceituais 
Linha D'Água (Online), São Paulo, v. 33, n. 1, p. 9-29, jan.-abr. 2020

Economia, muitas informações só podem ser depreendidas por uma análise mais atenta dessas denominações, o que pode explicar e evidenciar, quase sempre, a motivação cognitiva, ou seja, a intenção do emissor/autor ao escolher tal unidade em detrimento de outra. Consideremos, por exemplo, o termo flippagem ("flipagem"), que provém do verbo inglês to flip e pode ser traduzido como "sacudir, agitar", e em português passou a ser utilizado, de forma coloquial, como "estar muito entusiasmado", "enlouquecer", "pirar com algo" (Estou flipando com tudo isso!). Acrescido do sufixo -agem, que exprime a ideia de "ação ou resultado de ação", foi originado o termo flippagem, ou seja, a prática "alucinante e pouco comum" utilizada na bolsa de valores, de comprar, ganhar algo e já vender rapidamente.

Outro aspecto presente na terminologia da Economia é a variação, que, por ser uma característica inerente à unidade terminológica, conforme aponta $\mathrm{Ca}-$ bré (1999), pode manifestar-se em qualquer área de especialidade, inclusive na Economia.

Além da terminologia específica utilizada nessa área de especialidade, podemos destacar também as diferentes variantes presentes nesse domínio, como apresentamos a seguir, mais uma vez utilizando exemplos extraídos de Alves (2016, p. 51):

Tabela 1: Variantes denominativas da Economia

\begin{tabular}{|l|l|}
\hline colapso econômico & colapso da economia \\
\hline crise econômica & crise da economia \\
\hline crise financeira & crise das finanças \\
\hline crise cambial & crise do câmbio \\
\hline
\end{tabular}

Analisando os dados da tabela 1, evidencia-se que, muito mais do que uma variação morfossintática (de adjetivos a locuções adjetivas), temos, nessas variantes, informações conceituais distintas. Na utilização das variantes colapso econômico, crise econômica e crise financeira evidencia-se uma especificação conceitual de maior amplitude, conforme a classificação de Kageura $(2002)^{3}$, uma vez que esses termos

3 Kageura (2002), ao analisar a formação de termos das Ciências da Informação, distingue 25 relações interatermos e 20 padrões de especificação conceitual que se agrupam em 6 pontos de vista: igualdade, caráter funcional, parte e todo, atributos internos, relacional externo e outros.

COSTA, L. A. C., ALVES, I. M. Um estudo do termo fiscal na terminologia da Economia: processos de formação e informações conceituais 
Linha D'Água (Online), São Paulo, v. 33, n. 1, p. 9-29, jan.-abr. 2020

têm uma abrangência mais geral e, por esse motivo, são mais impactantes do que suas variantes colapso da economia, crise da economia e crise das finanças, respectivamente. Dizer que o país está em colapso econômico ou crise financeira transmite uma ideia de maior gravidade e maior alcance da situação, pois uma crise econômica e financeira de um país atinge muito mais do que apenas a Economia, influenciando também na saúde, educação, alimentação, entre outros aspectos.

Por outro lado, ao valer-se das locuções adjetivas "colapso da economia, crise das finanças, crise do câmbio", perde-se um pouco do alcance generalizado destacado nas variantes anteriores, ou seja, o impacto é suavizado. Dizer que há um colapso "da economia", que o país está passando por uma crise "das finanças", ou uma crise "da economia", transmite a ideia de que apenas essas áreas são afetadas, embora saibamos que um colapso da economia e uma crise financeira atingem outros fatores. Esses aspectos, no entanto, não estão refletidos nas variantes utilizadas, o que pode, claramente, representar uma motivação cognitiva do autor/escritor/ jornalista e ser causada por distintos fatores e não somente por progressão textual.

Para a análise que apresentaremos com as lexias formadas com o termo fiscal, consideramos o mesmo padrão de análise, isto é, verificaremos os processos de formação desses termos e as informações semânticas que transmitem.

\section{Metodologia}

Neste estudo, consideramos uma metodologia de trabalho quantitativa e qualitativa que consistiu em: (i) seleção dos termos utilizando as ferramentas Wordlist e Concord do programa computacional Wordsmith Tools, em um corpus constituído por textos (notícias) retirados do jornal Valor Econômico; (ii) análise qualitativa dos termos selecionados quanto aos seus processos de formação e às informações semânticas ou conceituais veiculadas pelas variantes.

Para a construção do corpus utilizado neste trabalho, selecionamos 150 textos/notícias, retirados do jornal Valor Econômico, todas as sextas-feiras, no período de janeiro de 2013 a dezembro de 2018. Os textos foram selecionados por meio do método de busca da palavra-chave fiscal, o que resultou em um corpus com um total de 10.387 palavras e 159 tipos de formação com esse adjetivo. No âmbito deste

COSTA, L. A. C., ALVES, I. M. Um estudo do termo fiscal na terminologia da Economia: processos de formação e informações conceituais 
Linha D'Água (Online), São Paulo, v. 33, n. 1, p. 9-29, jan.-abr. 2020

estudo, restringimos nossa análise a uma seleção de 50 unidades terminológicas, de modo a exemplificar como ocorrem essas formações no corpus coletado.

\section{Processos de formação e informações conceituais dos termos da Economia}

Por ser um sistema aberto, todos os dias novas palavras são incorporadas ao léxico, ao mesmo tempo em que outras palavras caem em desuso ou passam a ser utilizadas com um novo contexto de uso, uma nova significação. Essa mudança e constante expansão não ocorre apenas no léxico da língua comum. Para Gonçalves (2019, p. 123), "muito frequentemente, palavras são criadas na linguagem científica para cunhar novas realidades, como, por exemplo, 'pré-sal', que designa uma área de reservas petrolíferas posicionadas abaixo de uma profunda camada de sal".

Neste artigo, utilizando a ferramenta Concord do programa Wordsmith Tools, selecionamos ocorrências das unidades terminológicas utilizadas no domínio da Economia, mais especificamente, as unidades terminológicas construídas com o termo fiscal, como se pode observar na figura a seguir:

\begin{tabular}{|c|c|c|c|c|c|c|}
\hline \multicolumn{6}{|c|}{ C Concord } & \\
\hline File Edir & dit View Compute Settings Windows $\underline{H}$ elp & & & & & \\
\hline N & Concordance & Set Tag & Word \# Sent Sent Para Para & Sect Sect & $\%$ & \\
\hline 3 & de MÃ̄)dio e Longo Prazo do Ajuste Fiscal no Brasil, organizado pelo IBRE & & $217961^{\prime} 065^{\prime}$ & 0 65'CTE_09.12.12019/dez/11 & $66 \%$ & \\
\hline 4 & problemas em receitas e que 0 ajuste fiscal deve ser feito no lado das & & $195 \quad 544^{\prime} 030^{\prime}$ & 0 30'CTE_07.12.12019/dez/10 & $30 \%$ & \\
\hline 5 & ano que vem. â€œA falta de um ajuste fiscal afeta o desempenho da moeda & & $4791387 \quad 073^{\prime}$ & 0 73'CTE_20.12: 2019/dez/12 & $74 \%$ & \\
\hline 6 & Sem ajuste fiscal, turbul̃̃ancia externa ganha & & $409 \% \quad 00 \%$ & 0 0\%CTE_12.02.12019/dez/10 & $0 \%$ & \\
\hline 7 & Em palestra, Meirelles defende ajuste fiscal e a manutenÃßã£o das reservas & & $\begin{array}{llllll}7 & 0 & 12 & 0 & 1 \%\end{array}$ & 0 1\% CTE_18.03.12019/dez/11 & $1 \%$ & \\
\hline 8 & â€œEla Ã@) importante ao ajuste fiscal porque, no mÃ̃Cdio a longo & & $1.0573376^{\prime} 094^{\prime}$ & 0 94 CTE_14.12.12019/dez/11 & $94 \%$ & \\
\hline 9 & Sem ajuste fiscal, turbuläancia externa ganha & & $409 \% 00 \%$ & 0 0\% CTE_12.02.12019/dez/10 & $0 \%$ & \\
\hline 10 & Bolsonaro: medidas iniciais de ajuste fiscal Por Claudia Safatle â€" Valor 05 & & $\begin{array}{lllllll}7 & 0 & 11 & 0 & 1 \%\end{array}$ & 0 1\%CTE_05.10.12019/dez/10 & $1 \%$ & \\
\hline 11 & Ajuste fiscal deve dominar debate eleitoral & & $\begin{array}{lllll}3 & 0 & 2 \% & 0 & 1 \%\end{array}$ & 0 1\%CTE_29.06.12019/dez/11 & $1 \%$ & \\
\hline 12 & https://valor.globo.com/brasil/coluna/ & & $251748^{\prime} 026^{\prime}$ & 0 26'CTE_05.10.12019/dez/10 & $27 \%$ & \\
\hline 13 & Meirelles: Ajuste fiscal nÃ̃_o serÃ & & $405 \% \quad 0 \quad 1 \%$ & 0 1\% CTE_30.12.12019/dez/11 & $1 \%$ & \\
\hline 14 & aprova orÃßamento que prevÃa ajuste fiscal Por MarsÃ-lea Gombata, De & & $9019 \quad 01 \%$ & 0 1\%CTE_16.11.12019/dez/11 & $1 \%$ & \\
\hline 15 & Bolsonaro: medidas iniciais de ajuste fiscal | Brasil | Valor EconÃ'mico & & $259776^{\prime} \quad 027$ & 0 27 CTE_05.10.12019/dez/10 & $31 \%$ & \\
\hline 16 & carta de intenÃßÃues sobre o ajuste fiscal. "0 governo falou de reforma da & & 61425101091 & 0 91'CTE_29.02.12019/dez/10 & $91 \%$ & \\
\hline 17 & $\tilde{A} \odot$ a pior alternativa para o ajuste fiscal Por JoÃfo Guilherme Ometto & & $12 \quad 026,01 \%$ & 0 1\% CTE_29.01.12019/dez/10 & $1 \%$ & \\
\hline 18 & para serem feitos no prÃ $\tilde{A}^{3} \mathrm{ximo}$ ano fiscal. Ou seja, atravÃ@s desse tipo & & 50016101052 & 0 52' CTE_18.01.12019/dez/11 & $52 \%$ & \\
\hline 19 & no mesmo perÃ-odo do ano fiscal anterior. A empresa informou & & $8309^{\prime} \quad 026^{\prime}$ & 0 26'CTE_19.10.12019/dez/11 & $24 \%$ & \\
\hline 20 & a ser registrada no acumulado do ano fiscal de 2019 , marcado para terminar & & $26166^{\prime} 05^{\prime}$ & 0 85'CTE_02.11.12019/dez/11 & $85 \%$ & \\
\hline 21 & , feminino e famÃ-lia. Para 0 ano fiscal 2019 completo, a P\&G espera & & $2801119^{\prime} 088^{\prime}$ & 0 88'CTE_19.10.12019/dez/11 & $89 \%$ & \\
\hline 22 & obteve no segundo trimestre do ano fiscal de 2019 , encerrado em 30 de & & $46 \quad 0 \quad 55^{\prime} \quad 0 \quad 15^{\prime}$ & 0 15'CTE_02.11.12019/dez/11 & $15 \%$ & \\
\hline 23 & fim de seu primeiro trimestre do ano fiscal 2019 com lucro lâ-quido de US\$ & & $\begin{array}{llllll}48 & 0 & 57^{\prime} & 0 & 15^{\prime}\end{array}$ & 0 15'CTE_19.10.12019/dez/11 & $14 \%$ & \\
\hline 24 & , restringindo a autonomia fiscal dos Estados e municã-pios. 0 & & $8653187^{\prime} 08^{\prime}$ & $08^{\prime}$ CTE_$_{-}$18.01.12019/dez/11 & $90 \%$ & \\
\hline 25 & fiscais, recentralizando a autoridade fiscal no paÃ-s e, consequentemente, & & $8563164^{\prime} 088^{\prime}$ & 0 88'CTE_18.01.12019/dez/11 & $89 \%$ & \\
\hline
\end{tabular}

Figura 1: Unidades terminológicas construídas com o adjetivo fiscal

COSTA, L. A. C., ALVES, I. M. Um estudo do termo fiscal na terminologia da Economia: processos de formação e informaç̃óes conceituais 
Linha D’Água (Online), São Paulo, v. 33, n. 1, p. 9-29, jan.-abr. 2020

Posteriormente, dentre as 159 construções selecionadas, consideramos uma pequena amostra constituída por 50 das unidades terminológicas mais frequentes, conforme apresentamos na tabela 2:

Tabela 2: Exemplos de unidades terminológicas da Economia formadas com o termo fiscal

\begin{tabular}{|c|c|c|}
\hline $\begin{array}{l}\text { Formações com duas } \\
\text { unidades }\end{array}$ & $\begin{array}{l}\text { Formações com três } \\
\text { unidades }\end{array}$ & $\begin{array}{l}\text { Formações com mais de } \\
\text { três unidades }\end{array}$ \\
\hline armadilha fiscal & ajuste fiscal recessivo & $\begin{array}{l}\text { crime de responsabilidade } \\
\text { fiscal }\end{array}$ \\
\hline autonomia fiscal & $\begin{array}{l}\text { consolidação fiscal } \\
\text { moderada }\end{array}$ & disciplina na área fiscal \\
\hline benefício fiscal & execução fiscal federal & medida de ajuste fiscal \\
\hline bomba fiscal & prêmio fiscal político & $\begin{array}{l}\text { medida de austeridade } \\
\text { fiscal }\end{array}$ \\
\hline calote fiscal & resultado fiscal primário & medida na área fiscal \\
\hline ciclo fiscal & & modelo de cobrança fiscal \\
\hline cidadania fiscal & & plano da ineficiência fiscal \\
\hline crise fiscal & & plano de recuperação fiscal \\
\hline déficit fiscal & & ponto de vista fiscal \\
\hline desastre fiscal & & $\begin{array}{l}\text { programa de incentivo } \\
\text { fiscal }\end{array}$ \\
\hline desequilíbrio fiscal & & $\begin{array}{l}\text { programa de reequilíbrio } \\
\text { fiscal }\end{array}$ \\
\hline deterioração fiscal & & $\begin{array}{l}\text { regime de recuperação } \\
\text { fiscal }\end{array}$ \\
\hline disciplina fiscal & & $\begin{array}{l}\text { representação fiscal para } \\
\text { fins penais }\end{array}$ \\
\hline drama fiscal & & sigilo bancário e fiscal \\
\hline \multicolumn{3}{|l|}{ escrituração fiscal } \\
\hline \multicolumn{3}{|l|}{ estrangulamento fiscal } \\
\hline \multicolumn{3}{|l|}{ guerra fiscal } \\
\hline incentivo fiscal & & \\
\hline
\end{tabular}

(continua)

COSTA, L. A. C., ALVES, I. M. Um estudo do termo fiscal na terminologia da Economia: processos de formação e informações conceituais 
Linha D’Água (Online), São Paulo, v. 33, n. 1, p. 9-29, jan.-abr. 2020

(continuação)

\begin{tabular}{|l|l|l|}
\hline $\begin{array}{l}\text { Formações com duas } \\
\text { unidades }\end{array}$ & $\begin{array}{l}\text { Formações com três } \\
\text { unidades }\end{array}$ & $\begin{array}{l}\text { Formações com mais de } \\
\text { três unidades }\end{array}$ \\
\hline isenção fiscal & & \\
\hline meta fiscal & & \\
\hline natureza fiscal & & \\
\hline neura fiscal & & \\
\hline pedalada fiscal & & \\
\hline penúria fiscal & & \\
\hline prisma fiscal & & \\
\hline problema fiscal & & \\
\hline questão fiscal & & \\
\hline reforma fiscal & & \\
\hline resultado fiscal & & \\
\hline rombo fiscal & & \\
\hline stress fiscal & & \\
\hline
\end{tabular}

Como se pode observar, as formações recorrentes são poliléxicas, isto é, constituídas por duas ou mais unidades léxicas. Por ser um adjetivo, não encontramos formações em que o termo fiscal tenha valor isolado, uma vez que seu significado se dá justamente na relação com outros elementos. Assim, observamos unidades terminológicas formadas por duas palavras: crise fiscal; por três palavras: execuções fiscais federais; e por três ou mais lexias, sendo as mesmas relacionadas por meio de preposições de, na e para: programa de reequilíbrio fiscal, medida na área fiscal, representação fiscal para fins penais.

Observamos que o adjetivo fiscal exerce, sempre, a função de adjetivo classificador ou classificatório, de acordo com a distinção proposta por Neves, que a seguir apresentamos:

COSTA, L. A. C., ALVES, I. M. Um estudo do termo fiscal na terminologia da Economia: processos de formação e informações conceituais 
Linha D'Água (Online), São Paulo, v. 33, n. 1, p. 9-29, jan.-abr. 2020

Quadro 1: Classificação dos adjetivos de acordo com Neves (2000)

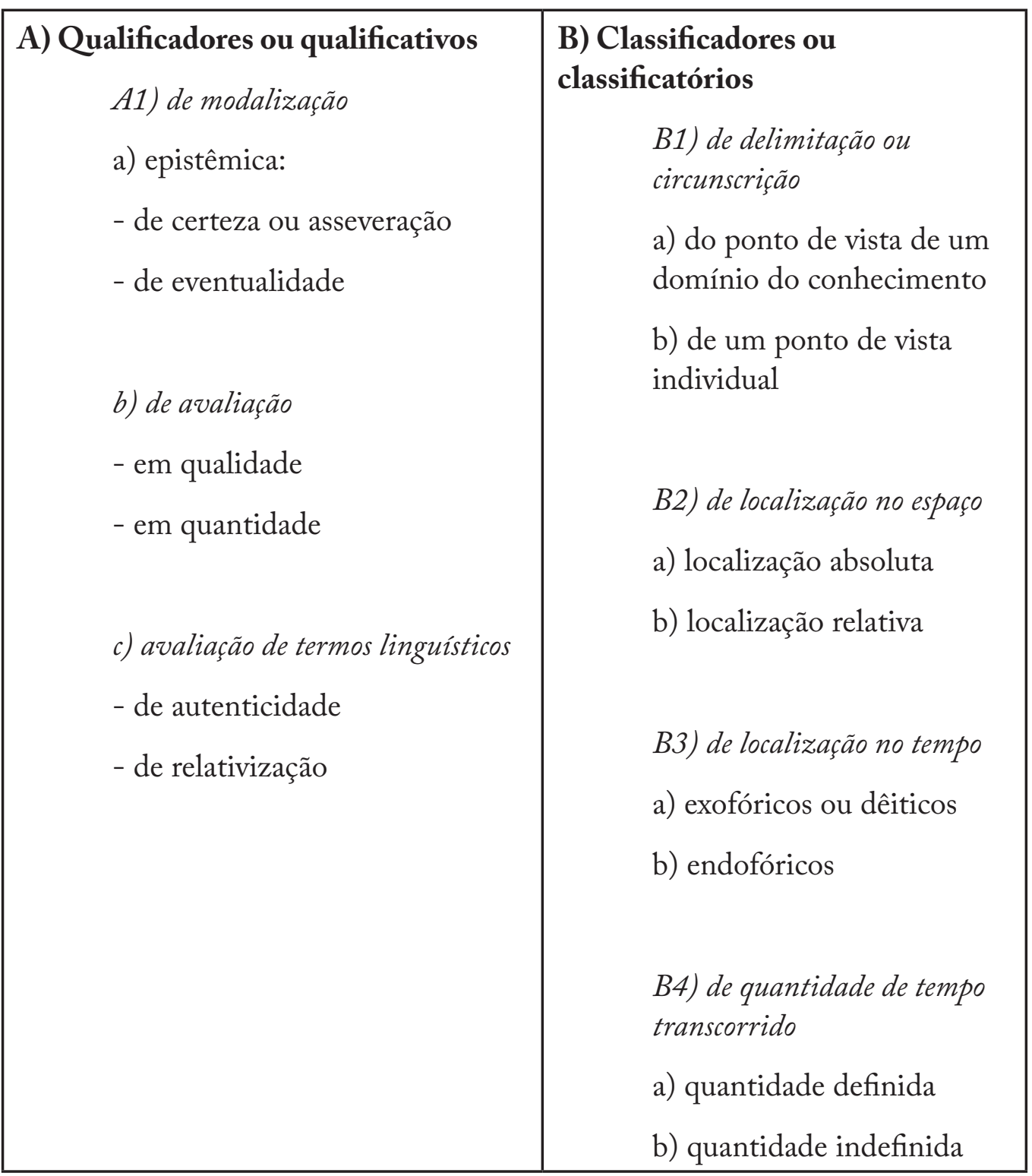

Segundo Neves (2000, p. 173), "os adjetivos são usados para atribuir uma propriedade singular a uma categoria (que já é um conjunto de propriedades) denominada por um substantivo". Essa atribuição de propriedade pode ser feita de duas formas: qualificando (adjetivos qualificadores ou qualificativos) e subcategorizando (adjetivos classificadores) o substantivo. Sobre os adjetivos classificadores, a autora explica que:

COSTA, L. A. C., ALVES, I. M. Um estudo do termo fiscal na terminologia da Economia: processos de formacç̃o e informacỡes conceituais 
Linha D’Água (Online), São Paulo, v. 33, n. 1, p. 9-29, jan.-abr. 2020

\begin{abstract}
Esses adjetivos colocam o substantivo que acompanham em uma subclasse, trazendo em si uma indicação objetiva sobre essa subclasse. Eles constituem, pois, uma verdadeira denominação para a subclasse e, portanto, são denominativos, e não predicativos, possuindo um caráter não-vago [...] (Neves, 2000, p. 186)
\end{abstract}

Destacamos essa distinção entre adjetivo classificador e adjetivo qualificador porque constatamos que, em todos os casos apresentados, o adjetivo fiscal não atribui uma característica ou qualifica o substantivo a que se refere; ao contrário, estabelece uma subclasse para esse substantivo, restringindo e delimitando o âmbito a que pertence, neste caso a Economia, e, por esse motivo, deve ser considerado um adjetivo classificador ou classificatório.

Como exemplos dos padrões de formação mais recorrentes com o adjetivo fiscal, destacamos:

\title{
a) Construções com duas unidades
}

1) Na prática, para formar o programa, o governo contou com aportes do Tesouro Nacional, a custos mais baixos que o das empresas - o que acabou por contribuir com a crise fiscal brasileira recente, na visão de alguns economistas, e também foi uma das motivações da União para pedir devolução de recursos ao banco. (BNDES: Linha voltada a PME supera $R$ \$ 1 bilhão em desembolsos mensais, 30/11/2017)

As unidades sintagmáticas constituídas por duas unidades se estruturam seguindo o padrão: substantivo + adjetivo classificador: armadilha fiscal, autonomia fiscal, benefício fiscal, ciclo fiscal, déficit fiscal, desequilíbrio fiscal etc.

\section{b) Construções com três unidades}

2) O presidente do BC destaca que o real se depreciou $20 \%$ desde maio de 2013, quando o Federal Reserve (Fed, o banco central americano) acenou com a perspectiva de reduzir o volume de compras de ativos. Ao mesmo tempo, Tombini lembra que o BC usou leilões de swaps cambiais e linhas de crédito para evitar volatilidade excessiva. $\mathrm{O}$ aperto monetário tem como objetivo conter as pressões sobre o câmbio para a

COSTA, L. A. C., ALVES, I. M. Um estudo do termo fiscal na terminologia da Economia: processos de formação e informações conceituais 
Linha D'Água (Online), São Paulo, v. 33, n. 1, p. 9-29, jan.-abr. 2020

inflação, enquanto a consolidação fiscal moderada visa reduzir a relação dívida/PIB no médio prazo. (Brasil ajustou politicas para lidar com transição global, diz Tombini, 05/12/2014).

Nas formações com três unidades, as unidades apresentadas seguem a estrutura: substantivo + adjetivo classificador + adjetivo qualificador (consolidação fiscal moderada) e substantivo + adjetivo classificador + adjetivo classificador (ajuste fiscal recessivo, execução fiscal federal, prêmio fiscal politico e resultado fiscal primário).

Em consolidação fiscal moderada, diferentemente das outras formações, observa-se que o adjetivo moderado, de caráter qualificador, tem a função de caracterizar ou predicar o substantivo consolidação, a que se refere. Ou seja, observa-se uma consolidação nos orçamentos e gastos públicos mais regrada e comedida e não tão forte ou de grande proporção.

\section{c) Construções com mais de três unidades}

3) Mas orbitam igualmente o plano da ineficiência fiscal os atuais instrumentos de arrecadação tributária, que contribuem para um sistema tributário de baixa qualidade. Nenhuma das propostas busca enfrentar, decisivamente, a enorme dificuldade de se cobrar devedores e sonegadores fiscais, que atualmente existe no país. (Contencioso fiscal e reforma tributária, 23/03/2018).

Quanto às unidades terminológicas constituídas por mais de três elementos, observamos que as mesmas seguem as seguintes estruturas: substantivo + preposição + substantivo + adjetivo classificador (plano da ineficiência fiscal), substantivo + adjetivo classificador + preposição + substantivo + adjetivo classificador (representação fiscal para fins penais) e substantivo + adjetivo classificador + conjunção + adjetivo (sigilo bancário e fiscal).

Com base nos exemplos supracitados, pode-se contatar que, embora haja diferenças a respeito do número de lexias e quanto ao padrão de estruturação e formação das unidades terminológicas, em todas as construções, fiscal foi empregado como adjetivo, não ocorrendo em nenhum dos casos mudança categorial desse termo. 
Em relação às propriedades semânticas do adjetivo, Silva et al (2013, p. 208) apontam que esse elemento é "capaz de persuadir e de manipular, uma vez que, ao atribuir uma propriedade, condiciona avaliações sobre um determinado ser", representado pelo substantivo.

Quanto às informações semânticas que, de alguma forma, estão relacionadas à escolha e vontade do falante/autor, neste caso os economistas que escrevem para o jornal Valor Econômico, convém destacar que, como aponta Gonçalves (2019, p. 124), ao criar ou empregar uma palavra morfologicamente complexa, há, nesse ato executado pelo falante, uma série de motivações de ordens distintas ou motivações múltiplas. A esse respeito, Basílio (2009) comenta:

[...] embora possamos apontar uma motivação sintática ou semântica de caráter mais imediato, a motivação para a formação de palavras corresponde à necessidade de utilização; e a utilização, é claro, envolve não apenas fatores sintáticos e semânticos, mas também outros níveis, como o da estrutura textual e fatores retóricos e expressivos, em diferentes predominâncias e combinações. (BASÍLIO, 2009, p. 31)

Dessa forma, podemos observar unidades formadas seguindo fatores mais sintáticos ou gramaticais, como por exemplo concordância nominal quanto ao gênero: ajuste fiscal recessivo, consolidação fiscal moderada; , e concordância nominal quanto ao número: pedaladas fiscais, problemas fiscais ${ }^{4}$; e unidades relacionadas a fatores retóricos e expressivos como as construções metafóricas: bomba fiscal, estrangulamento fiscal, neura fiscal e rombo fiscal, por exemplo.

Para Basílio (1987), essas criações e a utilização de construções morfológicas distintas estão relacionadas a fatores como: (i) necessidade de nomeação, isto é, cria-se uma denominação para nomear uma nova realidade; (ii) adequação ao contexto sintático, o que pode gerar mudanças de categoria de acordo com questões mais gramaticais, como por exemplo, controle fiscal dos bens e serviços/ fiscalização dos bens e serviços; (iii) intenções dos usuários da língua, o que inclui, como aponta Gonçalves (2019), uma função expressiva ou discursiva do falante que, por meio da

4 Embora, na tabela 2, por questão de organização, tenhamos optado por apresentar os termos em sua forma lematizada, no corpus, alguns deles aparecem no plural, como se pode observar em alguns dos contextos analisados.

COSTA, L. A. C., ALVES, I. M. Um estudo do termo fiscal na terminologia da Economia: processos de formação e informações conceituais 
Linha D'Água (Online), São Paulo, v. 33, n. 1, p. 9-29, jan.-abr. 2020

denominação, expressa seus propósitos, desejos e crenças, muitas vezes valendo-se de metáforas e outros recursos expressivos, para ressaltar aspectos que não poderiam ser destacados por meio da denominação literal e denotativa.

Relativamente ao emprego de metáforas no âmbito científico, segundo Costa (2007, p. 09), "se pensamos metaforicamente, como afirma a Linguística Cognitiva, toda a linguagem será afetada, seja a cotidiana, seja a terminológica". Isso ocorre porque a percepção, categorização e compreensão da realidade é mediada por filtros de caráter psicológico, antropológico e sociológico, interiorizados na memória de cada falante e que influenciam tanto na forma como o conhecimento é construído na cabeça do indivíduo, até o momento em que esse conhecimento é verbalizado por meio da fala ou da escrita (CABRÉ, 2008).

Para Silva (2003, p. 41), a metáfora não está restrita ao pensamento e linguagem comum, ela também pode estar presente nos domínios específicos, como as ciências e as tecnologias, pois:

As inovações tecnológicas são um dos lugares privilegiados da inovação metafórica, por duas razões. Primeiro, a necessidade de nomes para os novos elementos tecnológicos. Segundo, à medida que as novas tecnologias se vão tornando familiares, elas próprias constituem domínio-origem da metáfora (SILVA, 2003, p. 41).

Sobre a utilização de metáforas na Economia, autores como Enterría (2000), Alves (2001) e Vilela (2002) destacam que é muito comum e recorrente o uso de metáforas nessa língua de especialidade.

Alves (2001, p. 175) afirma que o economês é pleno de metáforas. E para Enterría (2000, p. 76), as metáforas da Economia são termos especializados que possuem rigor e precisão semântica, e sua presença em textos especializados possibilita não apenas a melhor propagação e divulgação da ciência, como favorece a comunicação entre especialistas e leitores leigos, uma vez que por meio das metáforas o leitor não-especialista pode compreender melhor o conceito especializado divulgado em textos altamente técnicos, principalmente quando essas metáforas se relacionam a outros domínios de conhecimento que lhe são mais conhecidos, como a Medicina (neura fiscal, stress fiscal), o futebol (pedaladas fiscais), entre outros. Essas metáforas, denominadas conceituais por Lakoff e Johnson (2002), com base

COSTA, L. A. C., ALVES, I. M. Um estudo do termo fiscal na terminologia da Economia: processos de formação e informações conceituais 
Linha D'Água (Online), São Paulo, v. 33, n. 1, p. 9-29, jan.-abr. 2020

nos princípios da Semântica Cognitiva, representam uma forma de conceitualizar um domínio de experiência, menos conhecido, o da Economia, em termos de outros, mais conhecidos pelo leitor, os da Medicina e do futebol.

A respeito do emprego desses recursos figurados nos discursos técnicos, Kocourek (1991, p. 167) ressalta que essa utilização não é incompatível com a busca de precisão terminológica que caracteriza o discurso terminológico. Da mesma forma, entendemos que, ao utilizar as expressões supracitadas, os autores, neste caso, economistas que escrevem no jornal Valor Econômico, procuraram evidenciar a gravidade e a importância da situação, o que não surtiria o mesmo efeito se fossem utilizadas expressões literais como: desvios fiscais, prejuizos fiscais, preocupação fiscal, problemas fiscais, situação fiscal etc.

Observemos, a seguir, como algumas dessas construções foram empregadas nas notícias divulgadas no Jornal Valor Econômico:

5) Pelas projeções apresentadas ontem pelo Ipea, o PIB da indústria deve crescer 2,1\% no terceiro trimestre na comparação com o período de abril a junho, com ajuste sazonal. A atividade de serviço $(0,9 \%)$ e a agropecuária $(1,1 \%)$ também devem exibir crescimento do valor agregado bruto por essa base de comparação. Desta forma, o PIB deverá crescer 1,6\% no acumulado deste ano, previsão um pouco acima da média das projeções de analistas do mercado, de 1,35\% segundo o mais recente Boletim Focus, do Banco Central. De acordo com Souza Junior, do Ipea, a recuperação não seria mais rápida por causa da "armadilha fiscal", que afeta expectativas de empresários e investidores. (PIB parece estagnado, mas retomada continua, diz Ipea, 29/08/2018).

Ao utilizar o termo armadilha fiscal, parece óbvio o propósito do autor de destacar que considera a política monetária do país como uma cilada, ou seja, um meio furtivo e não muito honesto de capturar e prejudicar empresários e investidores e, por esse motivo, impedir o crescimento da Economia. Uma clara analogia à definição de armadilha apresentada pelo dicionário Michaelis (2019), no qual, em sentido figurado ou por extensão, essa lexia corresponde a um "meio ardiloso de enganar alguém; cilada, cambapé, embuste, esparrela, rediosca".

COSTA, L. A. C., ALVES, I. M. Um estudo do termo fiscal na terminologia da Economia: processos de formação e informações conceituais 
Linha D'Água (Online), São Paulo, v. 33, n. 1, p. 9-29, jan.-abr. 2020

6) Na negociação do texto que vai a voto quando o stress fiscal deixar, Molon cedeu a partidos de oposição que queriam facilitar o histórico de navegação para a investigação criminal. Com argumentos como o que de $53 \%$ das pessoas que ganham até um salário mínimo e usam a internet o fazem também para assistir vídeos - uma grande parte deles, acessados em lan houses, para a preparação de concursos - o deputado tem angariado apoio ao texto. Enfrenta maiores resistências no PMDB, mas avalia que PT e PSDB tendem a rejeitar uma internet fatiada entre ricos e pobres. As contas a prestar ao eleitor leigo mais ajudam nessa convergência. $\mathrm{O}$ que atrapalha é a neura fiscal. (A urgência do marco civil engorda o superávit, 29/11/2013).

Neste excerto, o autor utiliza-se de duas metáforas constituídas pelos termos da Medicina stress e neura. Apresentada pelo dicionário Michaelis (2019), neura aparece como uma expressão coloquial, uma redução de neurastenia, que na Medicina e na Psicologia pode ser definida como (i) perturbação psíquica em que predomina estado de inatividade, fadiga intensa, alternância de humor, hipocondria e crises de histerismo e, em uma segunda acepção, pode ser empregada no sentido figurado como uma "tendência à irritação e ao pessimismo; neura". Sobre a utilização de termos da Medicina no discurso da Economia, Alves (2016) aponta que:

[...] desse entrelaçamento resultam termos em que o elemento determinado do sintagma nominal corresponde ao termo emprestado da Medicina, em uso metafórico, e o elemento determinante, de caráter adjetival, refere-se à área da Economia. Essa estrutura, sem ser rígida, é predominante em textos da Economia (ALVES, 2016, p. 52)

7) Os grandes empreendedores tinham à disposição os favores tributários e o crédito subsidiado dos bancos. Era um regime de partilha. Dividiam o bolo em dez partes, nove iam para os graúdos, e o povão ficava satisfeito com a sua fatia. Enquanto o preço das commodities estavam altos, os limites dessa lógica de cooptação ficaram ocultos. Quando os preços desabaram, o governo Dilma tentou dar sobrevida artificial a esse modelo, recorrendo a um Keynesianismo 5 vulgar. Uma

5 ECON Conjunto de conceitos econômicos proposto pelo economista inglês John Maynard Keynes (1883-1946), fundador da macroeconomia, que mudou radicalmente a visão de como as economias devem ser dirigidas, defendendo a garantia de emprego pleno e o controle da inflação. (MICHAELIS.UOL.COM.BR)

COSTA, L. A. C., ALVES, I. M. Um estudo do termo fiscal na terminologia da Economia: processos de formação e informações conceituais 
Linha D'Água (Online), São Paulo, v. 33, n. 1, p. 9-29, jan.-abr. 2020

das consequências foram as pedaladas fiscais que permitiram o impeachment $\mathrm{da}$ presidente. Assim chegamos até aqui. ("Novo governo pode radicalizar a concorrência", diz Mangabeira Unger, 14/12/2018)

O termo pedalada fiscal começou a ser usado no governo de Dilma Rousseff, sendo esse também o motivo que, possivelmente, culminou em seu impeachment. Trata-se, claramente, de uma metáfora conceitual que faz analogia com o futebol, uma vez que, segundo o dicionário Michaelis (2019), pedalada representa um "tipo de drible em que o jogador passa os pés alternadamente sobre a bola, sem tocá-la, a fim de enganar o adversário" e, na Economia, ligado ao adjetivo fiscal, passou a significar um tipo de manobra pela qual a Presidente Dilma Rousseff pretendia "enganar o mercado financeiro" utilizando o repasse de um fundo para outro como forma de controlar as contas federais. De acordo com o site do Estadão ${ }^{6}$ :

A "pedalada fiscal" foi o nome dado à prática do Tesouro Nacional de atrasar de forma proposital o repasse de dinheiro para bancos (públicos e também privados) e autarquias, como o INSS. O objetivo do Tesouro e do Ministério da Fazenda era melhorar artificialmente as contas federais. Ao deixar de transferir o dinheiro, o governo apresentava todos os meses despesas menores do que elas deveriam ser na prática e, assim, ludibriava o mercado financeiro e especialistas em contas públicas.

Com base nos exemplos apresentados, pudemos constatar que o emprego de metáforas na linguagem da Economia é um recurso válido e bastante frequente, o que confirma, como aponta Vilela (2002, p. 87), que a linguagem da Economia, além de valer-se do uso recorrente da metáfora, também surpreende pela amplitude e sistematicidade assumidas por esse processo de construção linguística.

Sendo assim, muito mais que um recurso estilístico e expressivo, as metáforas constituem um meio de facilitar e propiciar a compreensão entre texto técnico/ especializado e leitor leigo, a comunicação entre especialistas e não-especialistas.

6 https://infograficos.estadao.com.br/economia/pedaladas-fiscais/

COSTA, L. A. C., ALVES, I. M. Um estudo do termo fiscal na terminologia da Economia: processos de formação e informações conceituais 
Linha D'Água (Online), São Paulo, v. 33, n. 1, p. 9-29, jan.-abr. 2020

\section{Considerações finais}

Ao analisar as ocorrências do termo fiscal na terminologia da Economia, pudemos constatar que este se configura como um adjetivo classificador ou classificatório, delimitando e circunscrevendo o ponto de vista de um domínio do conhecimento, a Economia.

Em relação ao processo de formação dos termos sintagmáticos apresentados, selecionados dentre as ocorrências do corpus, as construções mais recorrentes são as unidades formadas por duas lexias (substantivo + adjetivo classificador), seguidas pelas construções com mais de três unidades e relacionadas por meio de preposição e conjunção e, em terceiro lugar, as unidades terminológicas com três lexias, com estrutura seguindo o padrão: substantivo + adjetivo classificador (fiscal) + adjetivo classificador.

Além das expressões com sentido literal, observamos que é recorrente a utilização de metáforas na Economia, o que comprova que os recursos expressivos como a metáfora, metonímia e outras figuras de linguagem não estão restritos ao pensamento e à linguagem comum, mas podem também estar presentes nos domínios específicos, das ciências e das tecnologias, muitas vezes possibilitando o processo de compreensão do leitor não-especialista a respeito de conceitos e linguagem altamente complexos e especializados.

Destacamos que, na TGT (Teoria Geral da Terminologia), ao perseguir o propósito da linguagem especializada como uma linguagem unívoca e sem ambiguidades, a metáfora foi colocada à margem, uma vez que era vista como um fator polissêmico que não deveria ser considerado na linguagem especializada.

Entretanto, como destacam as teorias mais modernas da Terminologia, como a Teoria Comunicativa da Terminologia (CABRÉ, 1999), as teorias de cunho cognitivo (TEMMERMAN, 2000; LAKOFF; JOHNSON, 2002), no processo de comunicação especializada não se pode excluir as características individuais, sociais e culturais do falante, fatores estes que influenciam diretamente tanto na forma como concebemos e construímos o conceito especializado, como na forma pela qual o transmitimos, seja pela fala ou escrita.

COSTA, L. A. C., ALVES, I. M. Um estudo do termo fiscal na terminologia da Economia: processos de formação e informações conceituais 
Linha D’Água (Online), São Paulo, v. 33, n. 1, p. 9-29, jan.-abr. 2020

Sendo assim, a metáfora também pode ser considerada como um elemento passível de ser apresentada e considerada nas terminologias, e neste trabalho pudemos observar várias formações, de caráter metafórico, com a participação do adjetivo fiscal, objeto de nosso estudo. Como afirma Temmerman (2000, p. 160), o raciocínio metafórico é responsável pela compreensão de novos fatos, processos ou outras categorias do saber científico, e pode explicar novas situações com o auxílio da criatividade do ser humano e de suas relações e experiências humanas para nomear e definir diferentes realidades e conceitos.

\section{Referências}

ALVES, I. M. As denominações da crise econômica mundial no entrecruzamento da Economia e da Medicina. Filologia e Linguistica Portuguesa. São Paulo, v.18, n.1, p. 43-64, 2016.

- Adjetivos de caráter opositivo na formação de termos sintagmáticos da Economia. Organon-Revista do Instituto de Letras da UFRGS. Rio Grande do Sul, v. 25, n.50, 2011.

Em torno de um jargão técnico: o economês. In: URBANO H; DIAS, A.R; LEITE, M.Q; SILVA, L.A; GALEMBECK, P. Dino Preti e seus temas: oralidade, literatura, mídia e ensino. São Paulo: Cortez, 2001.

BASÍLIO, M. Formação e classe de palavras no português do Brasil. São Paulo: Contexto, 2009.

. Teoria lexical. São Paulo: Ática, 1987.

BENVENISTE, E. Problèmes de linguistique générale. Paris: Gallimard, v. 2, 1974.

BÔAS, B. V. PIB parece estagnado, mas retomada continua, diz IPEA. In: jornal Valor Econômico. São Paulo: O Globo, 2018.

. BNDES: Linha voltada a PME supera R $\$ 1$ bilhão em desembolsos mensais. In: jornal Valor Econômico. São Paulo: O Globo, 2017.

CABRÉ, M. T. La Terminología: representación y comunicación: elementos para una teoría de base comunicativa y otros articulos. Girona: Documenta Universitaria, 1999.

COSTA, L. A. C., ALVES, I. M. Um estudo do termo fiscal na terminologia da Economia: processos de formação e informações conceituais 
Linha D’Água (Online), São Paulo, v. 33, n. 1, p. 9-29, jan.-abr. 2020

El principio de poliedricidad: la articulación de lo discursivo, lo cognitivo y lo lingüístico en Terminología. Ibérica, v. 16, p. 9-36, 2008.

COSTA, E. A. Um estudo cognitivo das metáforas geradas em um corpus jornalístico da economia. Dissertação de Mestrado. Universidade de São Paulo: Faculdade de Filosofia, Letras, e Ciências humanas, São Paulo, 2007.

ENTERRÍA, J. G. Últimas tendencias neológicas en la prensa económica. In: CABRÉ, M. T.; FREIXA, J; SOLÉ, E. La Neologia en el tombant de segle: I Simposi sobre Neologia (18 de desembre de 1998), I Seminari de Neologia (17 febrer de 2000). Barcelona: Institut Universitari de Lingüística Aplicada, 2000. p. 75-84.

ESTADÃO. Infográficos. Disponível em: https://www.estadao.com.br/infograficos/. Acesso em: 10.dez.2019.

FERNANDES, M. C. A urgência do marco civil engorda o superávit. In: jornal Valor Econômico. São Paulo: O Globo, 2013.

GONÇALVES, C. A. Morfologia: Linguística para o Ensino Superior. São Paulo: Parábola Editorial, 2019.

HOUAISS, A. Villar. M. Grande dicionário Houaiss Beta da lingua portuguesa. Rio de Janeiro: Instituto Antônio Houaiss, 2012. Disponível em: http://houaiss.uol.com.br/ Acesso em: 12.dez.2019

KAGEURA, K. The dynamics of terminology: A descriptive theory of term formation and terminological growth. Amsterdam/Philadelphia: John Benjamins, 2002.

KOCOUREK, R. La langue française de la technique et de la science. 2a ${ }^{\text {a }}$ ed. Wiesbaden: Brandstetter Verlag, 1991.

KRIEGER, M. G. Lexicografia: o léxico no dicionário. In: SEABRA, M. C.T. C. (Org.). O léxico em estudo. Belo Horizonte: UFMG, 2006.

LAKOFF, G.; JOHNSON, M. L. As metáforas da vida cotidiana. Trad. de Mara Sophia Zanotto et al. Campinas, São Paulo: Mercado de Letras, EDUC, 2002.

COSTA, L. A. C., ALVES, I. M. Um estudo do termo fiscal na terminologia da Economia: processos de formaçã̃o e informaç̦óes conceituais 
Linha D'Água (Online), São Paulo, v. 33, n. 1, p. 9-29, jan.-abr. 2020

MICHAELIS. Dicionário Michaelis da língua portuguesa, 2019. Disponível em: https://michaelis.uol.com.br. Acesso em: 10.dez.2019.

NEVES, M. H. M. Gramática de usos do Português. São Paulo: Editora UNESP, 2000.

REY, A. Essays on Terminology. Amsterdam/Philadelphia: Benjamins Translation Library, 1995.

RESENDE, A. L. O equívoco dos juros altos. In: jornal Valor Econômico. São Paulo: O Globo, 2018.

SAGER, J. C. Curso práctico sobre el processamiento de la terminología. Fundación German Sanches Ruiperez. Amsterdam/ Philadelphia: Jonh Benjamins Publishing Company, 1990.

SALLES, D; VIEIRA, C; BORGES, R. Novo governo pode radicalizar a concorrência, diz Mangabeira Unger. In: jornal Valor Econômico. São Paulo: O Globo, 2018.

SILVA, A. S. O que sabemos sobre a crise económica pela metáfora. Conceptualizações metafóricas da crise na imprensa portuguesa. Revista Media E̋ Jornalismo. Número temático "crise, memória e esquecimento", v. 22, n. 1, p. 11-34, 2013.

O poder cognitivo da metáfora e da metonímia. Revista Portuguesa de Humanidades. Braga: Faculdade de Filosofia da U.C.P., v. 7, n. 1/2, p. 13- 75, 2003.

TEMMERMAN, R. Toward new ways of Terminology description: The Sociocognitive Approch. Amsterdam: John Benjamins, 2000.

VILELA, M. Metáforas do nosso tempo. Coimbra: Livraria Almedina, 2002.

WÜSTER, E. Introducción a la teoría general de la terminología y a la Lexicografía terminológica. In: CABRÉ, M. T. (ed.) Barcelona: IULA-UPF, 1998.

Recebido: 16/12/2019.

Aprovado: 04/03/2020.

COSTA, L. A. C., ALVES, I. M. Um estudo do termo fiscal na terminologia da Economia: processos de formação e informações conceituais 